\title{
DISCURSOS PARLAMENTARIOS (Y OTRAS DISERTACIONES), DE ÓSCAR ALZAGA VILLAAMIL*
}

\author{
PARLIAMENTARY DISCOURSES (AND OTHER \\ DISSERTATIONS), ÓSCAR ALZAGA VILLAAMIL
}

\author{
Leonardo Álvarez Álvarez \\ Universidad de Oviedo
}

\begin{abstract}
SUMARIO: I. OSCAR ALZAGA, UN PROFESOR EN EL PARLAMENTO. 1.1. Los discursos parlamentarios de Alzaga.-1.2. Los roles de Alzaga en sus discursos parlamentarios. II. EL ROL DE ALZAGA COMO CONSTRUCTOR DE CONSENSOS.-2.1. Las bases del consenso y la ruptura de las dos Españas.- 2.2. La monarquía parlamentaria.-2.3. La cuestión religiosa.- III. EL ROL DE ALZAGA COMO ACADÉMICO Y COMO JURISTA.- 3.1. La Ley Orgánica del Tribunal Constitucional.- 3.2. La Ley Orgánica Reguladora de los Estados de alarma, excepción y sitio.- 3.3. La Ley Orgánica Reguladora del Estatuto de los Centros Escolares.-IV. CONCLUSIONES.
\end{abstract}

Palabras clave: Parlamento, consenso, tribunal constitucional, derecho a la educación

Keywords: Parliament, consensus, constitutional court, right to education

\section{I) ÓSCAR ALZAGA, UN PROFESOR EN EL PARLAMENTO.}

\subsection{Los discursos parlamentarios de Alzaga.}

En el año 2019, la Editorial Marcial Pons publicaba otro libro del Profesor Óscar Alzaga Villaamil, sin lugar a duda, uno de nuestros grandes Maestros del Derecho Constitucional. Con el título Discursos parlamentarios (y otras disertaciones), esa publicación tuvo lugar solo dos años después de que también viera la luz en la misma Editorial la segunda edición de su bien conocido Comentario Sistemático a la Constitución Española de 1978. Una obra con la que importaría al estudio de nuestro derecho constitucional una sistemática propia de la ciencia jurídica alemana. En ella ya avanzó en su primera edición de 1978 muchos de los problemas de carácter teórico-práctico a los que enfrentaría nuestra Constitución con el devenir del tiempo. Esta obra fue, desde luego, avanzada a su tiempo.

Si su Comentario Sistemático a la Constitución Española recogió la visión externa de un académico sobre el resultado constituyente, sus Discursos Parlamentarios muestran a un Alzaga protagonista del proceso de elaboración de la Constitución y de las leyes llamadas a desarrollarlo. Aquellos Discursos recogen sus intervenciones, como diputado de UCD, en defensa de las posiciones de partido sobre a) la elaboración de algunos de los preceptos más vidriosos de

\footnotetext{
* Este trabajo se publica conjuntamente en las Revistas Historia Constitucional y Teoría y Realidad Constitucional en el marco de la colaboración entre ambas
} 
nuestra Constitución (en la legislatura constituyente 1977-1979 y b) cómo se debía de proceder a su desarrollo normativo (en la primera y la segunda legislatura (1979-1982 y 1982-1986). Si algo queda claro de sus discursos es que no fue un simple profesor en política, fue un Profesor en el Parlamento. No fue un mero diputado, fue legislador.

Quizás para la comprensión de la labor que desempeñó Alzaga en su andadura parlamentaria susciten mayor interés sus discursos pronunciados entre 1977 y 1982 desde un gobierno en minoría. Esa labor la describió Victoria Prego en su Diccionario de la Transición:1 "Su actitud le hizo acreedor de ciertas reticencias en el seno del partido, pero su sólida formación jurídica le hizo imprescindible para el partido en momentos claves de la vida política". En este destacado papel tuvo gran relevancia que el partido percibiera sus escasos dotes para la politica y en su escaso interés en ocupar cargos de responsabilidad, habiendo rechazado, al menos tres veces, el cargo de Ministro (p. 14).

Eso permitió que pudiera asumir un cierto status de independencia dentro del partido y seguir desempeñando en sus discursos su condición de profesor. Como afirma nuestro Legislador: "casi todos los discursos parlamentarios aquí compilados están involuntariamente impregnados de la condición profesoral de quien hablaba" (p. 16). Lo cierto es que sus intervenciones ejercieron la función consustancial a una democracia parlamentaria: "la defensa racional de una tesis, bien ante parlamentarios a que se aspira a convencer para obtener sus votos, o impulsarlos hacia una enmienda transaccional... Un debate parlamentario que merezca tal nombre ha de situarse en las antípodas de los diálogos de sordos y estar presidido por razonamientos dialécticos de quien defiende una tesis frente a otras tesis que, de ordinario, también merecen respeto" (p. 15).

Esta es visión retrospectiva que aporta Alzaga casi 40 años después sobre sus propios Discursos parlamentarios en las páginas de su Presentación, cuya lectura permite constatar lo acertado de su juicio. Sin embargo, en ella, es lógico, no ha sido capaz de constatar algo, sin embargo, evidente para quienes han asistido al desarrollo de su pensamiento como académico con el devenir del tiempo, que plasmó a lo largo de un buen número de publicaciones y que impregnó posiblemente lo que ha sido su mayor contribución a nuestra ciencia: la Revista Teoría y Realidad Constitucional, que dirigió, con la imprescindible colaboración de prestigiosos profesores, desde 1998 hasta $2020 .^{2}$

"Razón de ser" del núm. 1/1998 y "Fin de etapa" del núm. 45/2020, escritos por el propio Alzaga, representan quizás el cuaderno de bitácora de su pensamiento académico. En su despedida como Director en 2020, exteriorizaría la misma filosofía que impregnó sus Discursos parlamentarios de 40 años atrás: el imperio de la dialéctica, el respeto la posiciones opuestas y su orientación hacia el realismo científico: "Estas páginas siempre han estado abiertas al ancho

\footnotetext{
1 Editorial Plaza \& Janés, 1999.
}

2 Una Revista en la que se recoge periódicamente una sección denominada semblanzas donde se recupera la obra de grandes maestros del Derecho político... tanto del XIX (Ramón de Salas, Antonio Alcalá Galiano, Manuel Colmeiro, Gumersindo de Azcárate, Vicente Santamaria de Paredes...) como del XX (Adolfo Posada, Fernando de los Ríos, Nicolás Pérez Serrano, Carlos Ruiz del Castillo, Manuel Garcia Pelayo....) 
abanico de visiones de altura sobre las materias que debíamos abordar, dando prioridad a la conexión Derecho Constitucional y realidad socio-política" (p. 14).

Al amparo de esta visión académica suscitan alguna curiosidad algunas de las posiciones defendidas en sus Discursos parlamentarios que reflejan quizás por qué, como afirmara Victoria Prego, su "sólida formación jurídica le hizo imprescindible para el partido en momentos claves de la vida politica". La firme defensa de las posiciones kelsenianas sobre la jurisdicción constitucional en su intervención en el proyecto sobre la Ley Orgánica del Tribunal Constitucional (p. 131 y ss.) y el recurso al decisionismo schmittiano en el debate sobre la Ley Orgánica de Estados de alarma, excepción y sitio (p. 163 y ss) expresaban dos esquemas de pensamiento que, hoy es posible saberlo, no vertebraban, en el fondo, la concepción académica de Alzaga.

Ello permite descubrir cómo su tarea en sus discursos parlamentarios fue poner sus sólidos conocimientos jurídicos al servicio de la defensa de posiciones de partido que, sin ser científicamente asumidas por él, si entraban, al menos, dentro de lo tolerable. El hecho de que reconociera en la Presentación de su Libro que se negó entonces a participar en defensa del modelo de Estado autonómico, por sus firmes convicciones federalistas (p. 14) no deja de confirmar esta impresión. La lectura de sus Discursos permite constatar cómo su formación jurídica le hubiera puesto en disposición de defender prácticamente cualquier posición con un grado de racionalidad y de capacidad de convicción tal que los hubieran convertido en dificilmente rebatibles por la oposición.

Sostenidos sobre los presupuestos de la dialéctica, comenzaban con la exposición de las tesis a rebatir, procediendo a desmontarlas a partir de argumentos teóricos y jurídicos (que más adelante se analizarán), para proceder posteriormente a la construcción de sus propios planteamientos. El lector de sus Discursos parlamentarios, como quizás también sus adversarios politicos entonces, acaba por convencerse de la idoneidad de unas tesis que, en principio, podrian ser dificilmente asumibles. Viendo la dinámica que se ha instalado en nuestro Parlamento en los últimos tiempos, el libro de Alzaga nos adentra en un modo de proceder que posiblemente ya no volverá a la vida pública.

\subsection{Los roles de Alzaga en sus Discursos parlamentarios}

En sus Discursos parlamentarios sería posible identificar dos grandes roles: a) el de constructor de consensos, que buscó plasmar en los textos normativos la transacción entre diferentes fuerzas políticas y b) el de académico y jurista. E1 primero de ellos se percibe, entre otros, en la conferencia pronunciada en el Club Siglo XXI, recogida en su Contribución de la oposición a una salida del franquismo (págs. 17 y ss.) y en sus intervenciones parlamentarias sobre los arts. 1,3 (monarquía parlamentaria) y 15 (libertad ideológica y religiosa) del proyecto de Constitución. Con la asunción de este rol, se situó en la estela del espíritu de la transición política, que él mismo tuvo la ocasión de encomiar el 20 de enero de 1977 en Madrid, en su conferencia pronunciada en el Club Siglo XXI.

Conforme a ese espíritu, contribuyó a abandonar la trágala que había inspirado la aprobación de nuestras constituciones históricas y a diseñar una Constitución abierta que permitiera que los distintos partidos politicos pudieran llegar a gobernar con el mismo texto constitucional. Sin embargo, su rol como 
constructor de consensos no fue incompatible con el rol de académico y de jurista que resulta más acentuado en otros discursos. Este rol se aprecia, entre otras, en sus intervenciones en los proyectos de leyes orgánicas: a) del tribunal constitucional, b) de estados de alarma, excepción y sitio y c) la reguladora del estatuto de los centros escolares. Que aquí se hayan seleccionado esos y no otros se debe a la originalidad de los planteamientos teóricos y jurídicos que introdujo en sede parlamentaria. Impropios de aquel tiempo, pero también de la actualidad.

Esto llama especialmente la atención porque Alzaga procedía de la escuela del Derecho Político. Desde la defensa de su tesis doctoral en 1972 sobre los Orígenes de la Democracia Cristiana en España ocupó en diferentes Universidades distintos puestos como profesor de Derecho Político, hasta la obtención de su Cátedra en la Universidad de Oviedo desde 1977 hasta 1979, en la que tuvo la ocasión de coincidir con el gran Maestro de constitucionalistas Ignacio de Otto y Pardo. Fue justamente en ese tiempo cuando Alzaga adquiriria la condición de diputado, algún tiempo después de las primeras elecciones democráticas en 40 años, celebradas el 15 de junio de 1977 a la legislatura constituyente. En enero de 1978 el ya Catedrático de Derecho Político en Oviedo se convirtió en diputado después de que Landelino Lavilla, Ministro de Justicia, nombrara Fiscal General del Estado a quien le había precedido en las listas por Madrid.

Se convirtió, así, en el único Catedrático de Derecho Político que tuvo UCD en sus filas. Sin embargo, contrariamente a otros profesores de la misma disciplina en las Cortes, ${ }^{3}$ transitó muy rápidamente hacia los presupuestos del Derecho Constitucional que imponía la aprobación de nuestra Constitución. Sería en 1979 cuando obtendría la Cátedra de Derecho Constitucional en la Universidad Nacional de Educación a Distancia. Su dominio de los presupuestos del Derecho Constitucional se aprecia en dos clases de argumentos que utilizó frecuentemente en defensa de sus posiciones: a) la doctrina extranjera más autorizada vinculada no solo a la teoría del Estado, sino a la de la Constitución, y b) el derecho comparado, basado en un sólido conocimiento del derecho positivo constitucional y legislativo, también de la jurisprudencia de otros Estados.

La lectura de sus Discursos parlamentarios permite aventurar la perplejidad que debió de suscitar en la oposición que introdujera en las discusiones sobre el proyecto de la Ley Orgánica del Tribunal Constitucional, de 1981, el modelo kelseniano de una jurisdicción constitucional como legislador negativo, sin menoscabo del principio de división de poderes. En un momento, además, en el que se pugnaba por reforzar el papel del legislador democrático en el Estado constitucional. Pero también la teoría schmitiana del dualismo del rango de las normas constitucionales en los debates sobre la Ley orgánica de estados de alarma, excepción y sitio, también de 1981, para poder defender la suspensión de derechos fundamentales y de las facultades ordinarias de los poderes del Estado en aras de la protección de un núcleo constitucional.

Pero a estos argumentos vinculados a la teoría del Estado y de la Constitución, desligados de exclusivos planteamientos del derecho político, se unieron otros, como se ha apuntado, vinculados a las fuentes del derecho comparado. Ello fue seguramente inevitable en aquellos momentos en los que no

\footnotetext{
3 Entre otros, Enrique Tierno Galván, Antonio López Pina, Luis Sánchez Agesta, Manuel Fraga Iribarte o Jordi Solé Tura.
} 
se había desarrollado aún en España una verdadera ciencia del derecho constitucional. Era necesario apoyarse, para poder construirla, en regulaciones y planteamientos de terceros Estados, como hicieron también los trabajos académicos que se publicaron durante los primeros años que tuvieron como propósito el estudio de nuestra Constitución. Eso Alzaga lo hizo en sus Discursos Parlamentarios con gran solvencia.

En ese contexto de construcción de nuestra disciplina científica, quizás lo que más llame la atención de sus Discursos es que en ellos fue ya capaz de anticipar una teoría de la interpretación constitucional a partir de los propios presupuestos normativos de la Constitución Española. Quizás entonces al alcance de pocos, solo hace falta recurrir a su intervención en defensa de la Ley Reguladora de los Centros Educativos de 1980 (pp. 147 ss.) para constatar cómo planteó una interpretación sistemática de los derechos fundamentales en liza. Una estructura normativa que le ayudó a justificar que la libertad de cátedra debía de encontrar su limite en el respeto al ideario educativo de los centros educativos de titularidad privada. La STC 5/1981 acabaría avalando su interpretación.

\section{EL ROL DE ALZAGA COMO CONSTRUCTOR DE CONSENSOS}

\subsection{Las bases del consenso y la ruptura de las dos Españas}

Como ha quedado dicho, uno de los principales roles que Alzaga desempeñó en sus Discursos parlamentarios fue el de constructor de consensos. Este rol fue especialmente perceptible en sus discursos pronunciados, sobre todo, durante la legislatura constituyente (1977-1979). Nuestro legislador recaló en el Congreso de los Diputados a principios de 1978, cuando la Ponencia ya había depositado ante la Comisión Constitucional el anteproyecto de Constitución. Fue a partir de ese momento cuando ejerció su labor constituyente, plenamente imbuido por el espíritu de consenso que se había instaurado entre los agentes politicos.

Sin embargo, ya había evidenciado, un año antes, la necesidad de crear una Constitución que rompiera la idea de las dos Españas y que fuera capaz de ejercer una función integradora frente la pluralidad de opciones políticas surgidas en democracia. Así se refleja en la conferencia que pronunció el 20 de enero de 1977 en el Club Siglo XIX ante más de mil personas, a la que asistió el Vicepresidente Alfonso Osorio y tres de los ministros del gobierno. Dieciséis dias después de que apareciera publicada en el Boletín Oficial del Estado la Ley 1/1977, para para la Reforma Politica, elogió la gran habilidad de Suárez por haber conseguido encauzar el tránsito hacia la democracia a través de una reforma pactada de las Leyes Fundamentales del Reino entre los franquistas y la oposición democrática.

Afirmaría que "El camino que más o menos intuitivamente, ha elegido el Gobierno a poco que se paren mientes, parece más afortunado. Entiendo que trata de aunar, de un lado, la legitimidad de las Leyes Fundamentales vigentes, válida para un sector de la población, a cuyo fin se ha respetado escrupulosamente el procedimiento de reforma previsto en el artículo 10 de la Ley de Sucesión, y de otro se suma la legitimidad democrática que emana de unas Cortes, auténticamente constituyentes, elegidas por sufragio universal en elecciones, que confiamos sean realmente libres y competitivas" (p. 19). 
No ignoraba con estas palabras los peligros que podría suponer para la convivencia una ruptura frontal con el franquismo, cuyos principios seguía siendo reconocidos aún por una no escasa parte de los individuos. Haberlo hecho así hubiera implicado revivir la idea de las dos Españas surgidas durante la Guerra Civil. Pero, como buen académico, entendió que no era suficiente que el pacto quedara relegado a la elaboración de la Ley que implicaba políticamente el acta de defunción del franquismo. Sabía de la necesidad de preservar ese pacto en el tiempo y que eso solo podría ser posible a través de un sistema jurídico de garantias que posibilitara el principio de seguridad mutua. Algo que un jurista sabe que solo lo aportan los procedimientos.

"Es decir, el principio que pregona que en un tránsito de estas características es más factible si se garantiza no ya el acceso al proceso decisorio estatal por parte de la oposición, hasta ahora marginada, sino la confortabilidad en la nueva situación de quienes venían monopolizando el poder. El principio de seguridad mutua, para que resulte operativo, exige el montaje de un sistema de garantías $\mathrm{y}$, en nuestro caso, no parece difícil descubrir la póliza de seguro de vida parlamentaria que se expide en beneficio de la oposición, en un Congreso de Diputados elegido por representación proporcional; mientras que la póliza de que a su vez es destinataria la vieja clase politica del sistema tiene forma de Senado elegido con arreglo a un sistema electoral mayoritario. Un sano eclecticismo" (p. 20).

Es probable que ese sistema de garantías creado por la Ley para la Reforma Politica y el resultado de las elecciones democráticas que se celebraron el 15 de junio de 1977 pudiera haber bastado para poder dotar de legitimación a las decisiones adoptadas por la mayoría parlamentaria victoriosa en los comicios favorable a la democracia. Era posible que la vieja legitimidad franquista hubiera aceptado que su derrota electoral le hubiera privado del suficiente protagonismo como para poner tener influencia en la elaboración del texto constitucional. Sin embargo, con gran inteligencia, Alzaga, siguió promoviendo el espíritu del pacto entre las fuerzas políticas en la elaboración de la Constitución, lo que se aprecia especialmente en la elaboración de los preceptos constitucionales relativos a la monarquía parlamentaria y en la denominada cuestión religiosa.

\subsection{La monarquia parlamentaria}

En una de las primeras ocasiones en las que nuestro legislador operó como constructor de consensos fue en el diseño de la jefatura del Estado prevista en el art. 1,3 CE (p. 33 y ss). Propuso algo que, en un principio, podría considerarse dificilmente factible: que dentro del Partido Socialista, netamente republicano, se abriera un debate interno destinado, en último extremo, a aceptar la monarquía como jefatura del Estado. Trató, en primer lugar, de poner en tela de juicio que la República pudiera ser entonces un elemento de cohesión de la sociedad: "transcurrido el tiempo y en la realidad en que nos movemos, podemos en verdad, afirmar que hoy día la República no es posible, porque no serviría de encuentro, de plataforma de convivencia de todos los españoles" (p. 35).

Justificó que ese elemento integrador podría desempeñarlo mejor la monarquía, presentando como elemento de convicción la indisoluble relación existente por entonces entre monarquía y democracia. La democracia que hacia 
posible la elaboración de una Constitución, como trataba de demostrar nuestro Profesor, encontraba su legitimación en la figura del Rey, que había jugado un papel esencial en la transición a aquella forma de Estado: "No es posible plantearse la forma politica que hoy interesa a España desconociendo la coyuntura por la que atraviesa el país. La democracia no sería posible sin la Monarquía y hoy es un hecho incontestable que la Monarquía tampoco sería posible sin la Democracia... hoy realmente la Corona es la gran fuente de la que han emanado las libertades públicas y la posibilidad de que estas Corten den al pueblo una Constitución genuinamente democrática" (p. 34 y s.).

Era probable que hubiera logrado convencer, amparado en el contexto histórico del momento, que el fundamento de legitimación de la democracia se encontraba en la monarquía, deshaciendo una premisa que parecía ser naturalmente más asumible: la ligazón entre democracia y república. Sin embargo, debió seguramente reparar en que sus esfuerzos por demostrar, en aquel momento histórico, la validez del binomio monarquía-democracia no era suficiente para que el Partido Socialista aceptara las tesis monárquicas para la configuración de la fórmula política del Estado en el art. 1,3 CE. Ello requería algo más. Fue ahí cuando nuestro jurista recurrió a su formación jurídica presentando algo que podría ser asumible por aquel partido.

Decidió plantear el modelo de monarquía republicana categorizado por el gran teórico del Estado Georg Jellinek (sin alusión en su discurso), del que Alzaga era, sin duda, conocedor. Una jefatura del Estado sin interferencia en el poder político: "El rey no está entre los poderes políticos, sino sobre los poderes políticos, en fórmula difícilmente perfeccionable. Ello le permite una imparcialidad en virtud de la cual la nave del Estado está en manos de pilotos que son políticos, que marcan el rumbo, sin que la Corona intervenga en la sustitución de esos pilotos o en el rumbo que en cada momento le dan. Ello, además, es posible mediante el hecho de que, en las Democracias coronadas, más que poder, lo que viene a haber en la jefatura del Estado es influencia" (p. 34).

Resulta evidente que Alzaga tenía en mente en su intervención parlamentaria la teoría del "poder neutro" de Benjamin Constant-no hay tampoco referencia a este autor en su discurso--por la que había transitado inevitablemente en su condición, entonces, de Catedrático de Derecho Político. Al amparo de estas tesis se entienden las palabras de Alzaga de que "Según el viejo dicho, el rey aconseja, anima y advierte" (p. 34). Era evidente que había conseguido presentar en su discurso un modelo de jefatura del Estado sostenido sobre la relación entre monarquía y democracia, pero, por el contrario, alejaba a aquélla del poder político efectivo, cesión ésta que podia satisfacer al Partido Socialista en la aceptación de la propuesta de redacción del art. 1,3 de la Constitución. Un punto intermedio entre dos visiones opuestas.

\subsection{La cuestión religiosa}

Un punto intermedio entre dos visiones opuestas fue también defendido en la redacción del art. 15 del proyecto de Constitución. Como sucedió con su intervención parlamentaria en defensa de la monarquía, articuló su discurso tratando de demostrar la improcedencia de la tesis defendida por el partido 
socialista: "La afirmación, entre otras auténticamente poco afortunadas, de que España habia dejado de ser católica, que se pronuncia en esta célebre sesión... es desafortunada porque no hay nada más desafortunado que venir a molestar, a herir los sentimientos de un sector importante de la población" (p. 43).

Sin embargo, en aras del consenso, renunció a la imposición de las tesis favorables a la confesionalidad del Estado, aun reconociendo que "UCD es un partido que recoge un amplio espectro de votos católicos... Pues bien, desde esta óptica, hemos de afirmar que no vamos a defender, ni aquí ni en ningún momento, la confesionalidad del Estado, ni pedir derechos para los católicos que no correspondan a los restantes españoles" (p. 43 y s.). "Nosotros lo que queremos... es saldar, mediante una fórmula afortunada, este largo pleito histórico, sin protecciones desaforadas para la Iglesia, sin ningún tipo de confesionalidad, pero también sin laicismos militantes que en momentos difíciles puedan degenerar en persecuciones aparatosas" (p. 72).

A pesar de que esta fórmula intermedia propuesta entre la confesionalidad y el laicismo favorable a la aconfesionalidad del Estado, justificó la necesidad de introducir la necesidad de fórmulas de cooperación expresamente con la Iglesia Católica. "¿Por qué, además, pensamos que es oportuna la referencia, la mención, bien sea de pasada a la Iglesia Católica en este párrafo? Porque creemos que es materia que afecta a los sentimientos más respetables de muchos españoles. A lo mejor esos españoles hoy somos minoría, no lo sé, pero aun siendo minoria, nuestros sentimientos son especialisimamente respetables. A esa sensibilidad también tiene que atender el legislador constituyente..." p. 45) Como había afirmado nuestro Catedrático de Derecho Politico en aquella conferencia pronunciada en el Club Siglo XIX, "un sano eclecticismo".

\section{EL ROL DE ALZAGA COMO ACADÉMICO Y COMO JURISTA}

\subsection{La Ley Orgánica del Tribunal Constitucional}

Sin ser, desde luego, incompatible con su rol como constructor de consensos que desarrolló sobre todo durante la legislatura constituyente, su papel se transforma cuando de lo que se trató fue de aprobar las leyes de desarrollo de la Constitución a lo largo de la primera legislatura. Es aquí cuando resulta especialmente perceptible su rol como académico, poniendo su sólida formación jurídica al servicio de la defensa de una determinada concepción de los órganos y de los derechos fundamentales que el diseño abierto de la Constitución permitía. Sus Discursos impartidos al amparo de este rol lo muestran cómodo, en un ámbito que le era más propio.

Eso se aprecia especialmente en su intervención en defensa de la necesidad de introducir un recurso previo de inconstitucionalidad frente los Estatutos de Autonomía en la redacción de la Ley Orgánica del Tribunal Constitucional, de 1981. Como se apuntó con anterioridad, resulta inevitable que aquella intervención llame la atención del lector tantos años después, teniendo en cuenta que sus posteriores desarrollos académicos se caracterizaron, entre otras premisas, por una firme defensa de la posición del legislador en el Estado democrático. Pero, quizás justamente por ello, se encargó de explicar en 2019, en la Presentación de su libro, los motivos de tan vehemente defensa de tal mecanismo llamado a controlar preventivamente la labor del Parlamento. 
En efecto, a pesar de haber reconocido su destacada intervención en la elaboración de los Estatutos de Autonomía catalán y vasco, desveló cómo "desde el vértice del Gobierno se nos cortocircuitó para aceptar soluciones tan inconstitucionales como el considerar competencias exclusivas de estas comunidades autónomas ciertas materias definidas en el artículo 149.1 de la Constitución como competencias exclusivas del Estado, lo que las convirtió en compartidas" (p. 14). De todos modos, a pesar de que quizás el recurso previo de inconstitucionalidad no fue tampoco entonces, cuando pronunció aquellos discursos, del todo coherente con las concepciones académicas de Alzaga, su defensa revela un grado de solidez tal, que la pertinencia de su introducción en la Ley Orgánica pudiera haber sido aceptada incluso por parte de sus más feroces críticos.

Articuló una defensa del mismo que se inició a partir de un primer argumento: la posición jerárquicamente infraordenada del legislador y de la rigidez del procedimiento de reforma constitucional que prohibía, naturalmente, a la ley proceder a su modificación: "nuestras Cortes son unas Cortes sometidas a derecho, porque nuestras Cortes no son, en sí mismas, constituyentes, no tienen reservada la facultad de, por vía de ley ordinaria, modificar los imperativos de nuestra Constitución, sino que la Constitución solamente es modificable... por los procedimientos especiales..." (p. 117 y s.).

Pero inevitablemente un académico como Alzaga era, en el fondo, conocedor de las debilidades de ese, su primer argumento. Sabía, por supuesto, que el legislador no se encontraba en menor medida sujeto a la Constitución en el caso de que se previera una intervención, por así decir, solo represiva del Tribunal Constitucional frente a una ley ya aprobada por el legislador. El derecho comparado, del que era conocedor, ofrecía ejemplos de ese modelo solo represivo que él trataba de rechazar. Sin embargo, sí se refirió en su discurso a los modelos que amparaban sus tesis: "En consecuencia, Señorias, nosotros prevemos un mecanismo, una competencia expresa del Tribunal Constitucional en este artículo 2, que podrá ser opinable, pero que está en la mejor y más moderna tradición del derecho comparado“ (p. 121).

Es más, incluso los postulados de Hans Kelsen sobre la jurisdicción constitucional, que seguidamente abrazaría en su discurso parlamentario, lo desdecian. Éste, con suma habilidad, los omitió en su intervención parlamentaria. Fueron los planteamientos de aquel autor austriaco los que le sirvieron a Alzaga, a modo de segundo argumento, para deshacer las reticencias que suscitaba en la oposición la posible injerencia del Tribunal Constitucional, órgano carente de legitimidad democrática, en la labor del legislador. Afirmó que ello "no encierra ninguno de los riesgos políticos que aquí se han insinuado" (p. 121).

Para desdecir las suspicacias de una presunta quiebra del principio de división de poderes defendió una tesis que debió generar un gran impacto en el debate parlamentario. Centró sus esfuerzos en lograr la aceptación del Tribunal Constitucional como un legislador más en el Estado democrático. Un legislador negativo. "Como decía Kelsen, quien puede anular una ley, en cierta medida asume funciones legislativas, porque tan importante es decretar una ley como derogarla" (p. 124). Fue aquí cuando volvió a recurrir a los más autorizados debates sobre la teoría de la jurisdicción constitucional, con el fin seguramente 
de atemperar el impacto que pudiera suscitar el reconocimiento de un nuevo legislador en el recientemente creado Estado democrático, parejo a aquel que se había pretendido encumbrar después del proceso de la transición política.

Apoyándose casi con toda seguridad en la clásica diferenciación entre el modelo de "argumentación política" y de "argumentación jurídica" de Martin Kriele-no existe alusión a éste en su discurso-trató de defender que el Tribunal Constitucional no intervenía como legislador negativo en el ámbito político del legislador, sino que interfería en el mismo con arreglo a parámetros jurídicos. Como diría, "estamos ante un órgano que va a intentar abordar en términos jurídicos facetas que tienen incluso su proyección en la esfera de lo político, porque el pueblo español quiere regir su convivencia con arreglo a la ley, que es la expresión de la voluntad popular” (p. 137).

\subsection{La Ley Orgánica Reguladora de los Estados de alarma, excepción y sitio}

Especial mención merece su intervención en el debate parlamentario sobre la tramitación de la Ley Orgánica 4/1981, reguladora de los Estados de alarma, excepción y sitio. En particular, su argumentación para rebatir la enmienda que trató de introducir en el proyecto el Partido Nacionalista Vasco, en el sentido de exigir un trámite de audiencia previa al gobierno de una Comunidad Autónoma para declarar los Estados excepcionales. Sus esquemas argumentales se sostuvieron sobre una conocida premisa "soberano es quien puede declarar el Estado de excepción” (p. 169). Resulta evidente para cualquier académico que nuestro Profesor optó en su discurso parlamentario por recurrir a las construcciones del destacado teórico del Estado y de la Constitución, Carl Schmitt.

En este punto, hay algo que llama la atención. Contrariamente a la explícita alusión que hizo a Hans Kelsen para avalar sus posiciones sobre la jurisdicción constitucional, Alzaga decidió omitir cualquier referencia a Schmitt: "Pero en el estado de excepción nos encontramos con la célebre afirmación que todos conocemos de un clásico del Derecho Político que dijo en frase celebérrima: "soberano es quien puede declarar el estado de excepción" (p.169). Es probable hubiera optado por tal decisión, inteligentemente, al percibir la elevada carga semántica que hubiera podido tener dicho autor en un debate parlamentario destinado a definir una concepción de los Estados excepcionales en el art. 116 $\mathrm{CE}$ que debian de realizarse, de manera inequivoca, en los contornos del principio democrático.

Sin embargo, la lectura de su discurso parlamentario permite evidenciar que la alusión a la premisa sobre la que se construía la teoría de Carl Schmitt: soberano es quien puede declarar el estado de excepción, no tuvo solo una finalidad retórica. Su intervención permite constatar que supo percibir con elevado grado de rigor metodológico y científico los presupuestos y las consecuencias que se derivaban de dicha teoria. Eso resultaba algo impropio de un simple Catedrático de Derecho Politico. Evidenciaba ya un manifiesto dominio de los esquemas de pensamiento vinculados al Derecho Constitucional. La premisa "soberano es quien puede declarar el estado de excepción" le sirvió para justificar teóricamente el art. $116 \mathrm{CE}$ en el principio de eficacia del ordenamiento. 
En efecto, el art. $116 \mathrm{CE}$ constituía para él el instrumento último para salvaguardar la existencia misma de la Constitución y del Estado: “...en un Estado de excepción estamos en presencia de una situación verdaderamente limite, verdaderamente extraordinaria, en que están amenazados bienes sustanciales de la comunidad y, en consecuencia, el mismo imperio del Derecho. Dicho en otros términos, puede estar en juego la permanencia misma del sistema democrático" (p. 179). En ello basó su rechazo al trámite de audiencia previa al presidente de una comunidad autónoma para la declaración de los Estados excepcionales. Pero, además, de la premisa "soberano es quien decide sobre el Estado de excepción", materializada en el razonamiento de Alzaga, desde un punto de vista teórico-jurídico, en el principio de eficacia del ordenamiento, derivó dos consecuencias, orgánicas y funcionales.

En lo que se refiere a las primeras, trató de justificar que el órgano llamado a intervenir principalmente en el Estado de excepción debía de ser el gobierno del Estado, en tanto sujeto políticamente homogéneo y expeditivo. Al respecto, afirma "Seamos serios, me dice el señor Vizcaya. Eso es lo que estamos intentando ser; ser absolutamente consecuentes con el espíritu del art. 116 de la Constitución; que se le impute la responsabilidad de afrontar las situaciones limites exclusivamente al Gobierno de la Nación..." (p. 182). "El principio de concentración de poder, señor Vizcaya, difícilmente es compatible con el mantenimiento de la Junta de Seguridad, por ejemplo, a la que se hace referencia en su enmienda como órgano clave de coordinación de las fuerzas de policía autónoma con los Cuerpos y Fuerzas de Seguridad del Estado, durante un Estado de excepción" (p. 179).

Pero en segundo lugar, nuestro Legislador deriva del principio de eficacia del ordenamiento, en el que justifica teóricamente el art. $116 \mathrm{CE}$, importantes consecuencias en lo que se refiere a sus funciones. Como argumentó: "Si precisamente es algo un estado de excepción, es la necesidad de desprenderse del corsé del Derecho en ciertos aspectos a la hora de posibilitar una respuesta flexible de la colectividad, de los poderes públicos, en situaciones realmente anormales" (p. 174) "Y normalmente se admite que es una reasunción de poderes que, de alguna manera dimanan de la Nación soberana, y que vuelven a emerger a través del Gobierno y del Parlamento de la Nación en circunstancias en que el orden jurídico habitual puede verse desbordado por los hechos" (p. 169).

Estas expresiones reflejan a un Alzaga plenamente imbuido del pensamiento de Schmitt, que parte de la distinción de dos planos en el seno del Derecho Constitucional, uno conformado por las normas del texto constitucional y otro por una legitimidad material ajena al mismo. Las facultades del art. $116 \mathrm{CE}$, de acuerdo con su pensamiento, implicarian el directo ejercicio de los poderes de la Nación soberana, sin sometimiento a las normas del texto constitucional que, en situaciones ordinarias, materializan el ejercicio de la soberanía prevista en el art. 1,2 CE a través de distintos órganos. Sin embargo, el razonamiento de nuestro Profesor suscita alguna cuestión. Casi 40 años después de aquellos discursos, al lector le asalta la duda de si asumía entonces verdaderamente aquella concepción del Estado y de la Constitución o si ello obedeció a encontrar argumentos adecuados, en aquel momento político, para desmontar las tesis de la oposición. Si este último fue su propósito, lo hizo con gran habilidad y con una sólida capacidad de convicción. 


\subsection{La Ley Orgánica Reguladora del Estatuto de Centros Escolares}

Es seguramente en su intervención parlamentaria en el Proyecto de Ley Orgánica Reguladora del Estatuto de los Centros Escolares, de 1980, donde se más aprecie su rol como jurista, labor a la que por entonces habia dedicado más de 13 años como abogado. Es cierto que en este proyecto de ley se desliza también su rol como constructor de consensos, remitiéndose a alguno de los asuntos más vidriosos que habían presidido la elaboración de la Constitución, la conciliación entre el modelo de enseñanza pública y privada en el art. $27 \mathrm{CE}$ : "si mi partido y mi grupo parlamentario tienen una gran razón de existir es el intento de superar la dualidad entre las dos Españas" (p. 148).

$\mathrm{Su}$ intervención parlamentaria no se centró en ofrecer principios vinculados a la teoría del Estado y de la Constitución para la interpretación de las normas constitucionales, tal como había sucedido con sus discursos relativos a la Ley Orgánica del Tribunal Constitucional y a la de los Estados de alarma, excepción y sitio, que reflejaron a un Alzaga académico. Lo que destaca de su intervención en la Ley Orgánica Reguladora de Centros Escolares es haber ofrecido una sugerente técnica interpretativa de textos normativos, que contribuyó a delimitar los derechos fundamentales que se proyectaban en la relación educativa. No por casualidad, el Tribunal Constitucional le daría la razón en la STC 5/1981 en lo que se refiere a su defensa de la tesis de que el ejercicio de la libertad de cátedra debía de respetar el ideario educativo de los centros de titularidad privada.

Quizás no sean aquí tan relevantes los argumentos vinculados al derecho comparado que vuelve a utilizar para la defensa de sus tesis: "Señorias, yo no intento inundar a esta Cámara con citas de derecho comparado, pero existen. La Ley vigente francesa, la llamada Debray de 31 de diciembre de 1959, establece que los profesores deberán respetar el carácter propio de cada centro, y la interpretación dada a ese precepto en Francia es paralela, es absolutamente coincidente con el respeto que se pide en el artículo 15 para el ideario en los Centros privados. Y, por último, voy a citar una sentencia dictada por la Corte Constitucional italiana el 29 de diciembre de 1972 ... en la que Tribunal rechazó el recurso del profesor separado y estableció en sus considerandos que la libertad científica en los establecimientos docentes privados se encuentra sometida a los limites necesarios para alcanzar los fines perseguidos por los mismos" (p. 154).

Lo más destacable fue su capacidad para delimitar los derechos a la libertad de cátedra del art. 20,1 c) y la libertad de enseñanza del art. 27,6 CE, varios años antes de que se publicaran relevantes trabajos académicos sobre la libertad de enseñanza. ${ }^{4}$ Sin apenas material científico de referencia, Alzaga ya adelantó en 1980 una interpretación que sería pacíficamente asumida por el debate académico. Su tesis trató de demostrar la diferente delimitación entre la libertad de cátedra y el derecho a la educación que se desarrollaba en centros públicos (art. 27,5 CE) y la que tenía lugar en centros de titularidad privada, consecuencia del ejercicio de la libertad de enseñanza (art. 27,6 CE).

\footnotetext{
4 Entre ellos, el del administrativista Antonio Embid Irujo, Las libertades en la enseñanza, ed. Tecnos, 1982 y el del constitucionalista Alfonso Fernández- Miranda Campoamor, De la libertad de enseñanza al derecho a la educación, ed. Centro de Estudios Ramón Areces, 1988.
} 
Ya fue consciente de que en la educación pública y privada, concurría una diferente naturaleza de normas constitucionales, que según su parecer de entonces "entran en colisión" (p. 152). Es cierto que con esta expresión venía a defender la tesis de una colisión entre normas constitucionales, y su consecuente resolución a partir de la teoría de la ponderación. Estas dos premisas podrian ser fácilmente argumentables desde la perspectiva de una división del objeto del derecho constitucional en dos planos, a partir de la que construyó su intervención ya analizada en la Ley Orgánica reguladora de los Estados de alarma, excepción y sitio. Sin embargo, vista la intervención en su contexto, Alzaga no defendía, en realidad, la técnica de la colisión y de la ponderación en el ámbito de las libertades educativas, sino que se abogaría por la de la delimitación de los derechos, vinculada a la identidad de rango de las normas constitucionales propia del positivismo kelseniano, al que había recurrido en su discurso sobre la Ley Orgánica del Tribunal Constitucional.

Que se inclinara por la técnica de la delimitación y no de la ponderación de los derechos fundamentales se aprecia en el esquema de normas constitucionales desde el que se construiría su solución. Mantuvo que "En los centros docentes públicos no hay el menor problema respecto de la libertad de cátedra". Todo lo más, la libertad de cátedra podría entrar en colisión con el derecho a la educación de los discentes: "No hay al menos otro problema que el del nivel del alumnado, es decir dimanante de la edad de los alumnos. Porque el artículo 20.4 de la Constitución hay que tenerlo presente: Estas libertades...tienen su limite en (hay una enumeración de los límites), y al final se dice: el derecho a la protección de la juventud y de la infancia" (p. 150 y s.).

De ello venía a deducir, acertadamente, que la interdicción del adoctrinamiento era un límite que imponía el derecho a la educación del art. 27,1 $\mathrm{CE}$ a la libertad de cátedra. Por ello mantenía que "no en vano en la Universidad con adultos la libertad de cátedra es genuina, es prácticamente entera, es la auténtica y absoluta libertad de cátedra" (p. 151). Sin embargo, supo ver que el esquema de normas constitucionales que debian de ser manejadas por el jurista en el plano de la educación que se desarrollaba en centros privados era distinta. Había que introducir en el entramado de normas una que no estaba llamada a operar en la educación pública: el ideario educativo: “a ese profesor de centros públicos se le reconoce en este precepto su libertad docente sin especiales cortapisas, porque en el centro público en cuestión, como saben bien sus Señorias, según este proyecto de ley no existe ideario" (p. 151).

Seguramente hubiera sido desproporcionado exigirle que fuera capaz de aceptar entonces que en los centros públicos sí existía un ideario, como reconocería con posterioridad la STC 5/1981: el previsto en el art. 27,2 CE. Sin embargo, ya supo ver, de alguna manera, que el ideario reconocido por la libertad de enseñanza del art. 27,6 CE no hubiera tenido nada que ver materialmente con el del art. 27,2 CE. Pero tampoco formalmente. En efecto, alcanzó a percibir que el ideario de los centros docentes de titularidad privada integraba el contenido de un derecho fundamental. Eso es lo que le llevó a entender que este ideario educativo entraba dentro del ámbito de la norma del art. 20,4 CE que reconoce que los derechos previstos en él, entre ellos, la libertad de cátedra, tenían el límite en los derechos reconocidos en el Título I. Y no así, siguiendo el iter discursivo de Alzaga, el ideario educativo de los centros públicos, que no ejercian, en sentido estricto, un derecho fundamental. 
Afirmó acertadamente: "En suma, tenemos que no se puede usar de la libertad de cátedra contra el ideario medular de una institución privada de enseñanza, porque eso atenta a la libertad de enseñanza y, consiguientemente, es inconstitucional. Va contra el artículo 27 de la Constitución y va contra el artículo 20,4 de la Constitución" (p. 153). Pero, sin embargo, no apostó por el sacrificio de la libertad de cátedra, a lo que quizás le hubiera llevado el inadecuado empleo de la técnica de la ponderación. Llevó a cabo una adecuada delimitación de los derechos en liza, entendiendo que el ideario educativo no exigía una renuncia a la libertad de cátedra, sino una proporcional limitación: "Así es que hay ideario educativo propio del centro, y lo que pide el artículo 15 es que los enseñantes lo respeten, no que comulguen con él” (p. 152).

\section{CONCLUSIONES}

Es probable que en 2019, cuando han aparecido publicados sus Discursos Parlamentarios (y otras disertaciones) haya sido posible apreciar retrospectivamente la verdadera entidad de la tarea de Óscar Alzaga como Legislador. Fue capaz de poner su sólida formación como académico y como jurista al servicio de la defensa de posiciones de partido que, hoy es posible saberlo, no definirian su pensamiento académico, pero que para él entraban dentro de lo tolerable. Para ello hubo de paliar con gran solvencia las deficiencias que, por entonces, tenía nuestra disciplina, que no había desarrollado esquemas de pensamiento aplicables a una Constitución racional-normativa y abierta a distintos programas políticos. Y lo hizo, de un lado, importando para su interpretación las más relevantes teorías del Estado y de la Constitución que se habian desarrollado, sobre todo en Europa.

Unas teorias que no eran, en realidad, compatibles metodológicamente entre sí, dado que se apoyaban en distintos conceptos de Constitución, no siempre conciliables con el que se derivaba de la Constitución Española de 1978 recientemente aprobada, pero que supo compatibilizar adecuadamente. E1 seguimiento de su argumentación permite constatar que aquellas teorias no fueron importadas al debate parlamentario con una finalidad solo retórica, sino que reflejaron un muy detenido conocimiento de las mismas y los presupuestos sobre los que se construían. Por otro lado, sus discursos parlamentarios evidenciaron también un solvente conocimiento del derecho comparado, que le sirvió para avalar sus posiciones.

Nuestro Legislador no solo comenzó a construir las bases científicas de nuestra disciplina en sus Discursos parlamentarios a partir de teorías y soluciones manejadas en otros ordenamientos. Ello hubiera sido ya una propuesta metodológica muy aceptable, y en la que se basaron los primeros trabajos científicos sobre la Constitución Española. Alzaga supo desarrollar una interpretación del texto constitucional desde sus propios presupuestos, presentando soluciones que posteriormente serian avaladas por la jurisprudencia del Tribunal Constitucional y por los posteriores estudios académicos. Ello refleja que los discursos de Alzaga fueron avanzados a su tiempo.

40 años después de pronunciados aquellos discursos es inevitable que al lector le suscite la duda de si hubo en el Parlamento de entonces la capacidad suficiente para poder comprender en toda su extensión los planteamientos 
académicos de Alzaga y para poder rebartirlos. Lo único cierto es que comenzó a construir ya en sus Discursos Parlamentarios las bases científicas de nuestra disciplina que posteriormente hubo de plasmar a lo largo de su dilatada carrera académica, que nunca interrumpió durante su estancia en el Parlamento. 